of persons who might have been rehoused in ground-floor accommodation. The patients themselves thought that the interests of the family had to be recognized, and were determined to be as independent as possible. The authors conclude that the number of such persons under the age of 35 was small and that in almost every respect they fared better than their elders, particularly in terms of medical care and of opportunities for employment. They confirmed the statement in the Piercy Report" that "doctors still need to be better informed of the scope, nature and potentialities of rehabilitation," and suggested that local authorities needed to know more about the chronic sick and disabled in their areas. They considered that a hospital unit of 60 beds should be adequate to serve the needs of a population of about 300,000 .

It is difficult to determine precisely the size of the problem. The number of substantially and permanently handicapped people aged between 16 and 65 years in Great Britain at the end of 1964 on the registers of local authorities was 164,000. In 1963 the Ministry of Pensions and National Insurance recorded 225,800 people in Great Britain between the ages of 18 and 65 years ( 60 for women) who had been receiving sickness benefit for two years or more, with perhaps a further 100,000 sick or handicapped people of this age group in receipt of National Assistance allowances for the same period. There are thus, possibly, some 500,000 people of working age in Great Britain so handicapped as to be incapable of paid employment, though with the exclusion of mental illness and mental subnormality the estimate might fall to 370,000 . The most unsatisfactory position relates to the thousands of young chronic sick patients, of whom perhaps only one-tenth are in special units designated for their care. Many of the remainder are scattered through geriatric wards. Though some of these are middle-aged, this is no excuse for a lack of interest and drive that is an unhappy reflection on our hospital service.

It is often said that many such patients prefer to be in hospital wards, however unsuitable, near their homes and former environment. But this is not always borne out by experience, for many of the excellent homes provided by voluntary organizations attract patients from all over the country, who soon adapt themselves to the new community in which they are placed. This type of patient often comes to the hospital service as a social emergency. Consequently there might well be established in each region a hospital unit, or units, for the young chronic sick which would provide not only a hospital ward with single and double rooms and cubicles but occupational rooms of sufficient variety to recognize that the patient is usually going to spend the remainder of his days in that hospital, and needs an environment appropriate to his condition and to his mental faculties and interests. Such units might be of $25-50$ beds, and without doubt relatives and friends would not resent travel if they were satisfied by the better conditions for the patients. The unit for young chronic sick could be in the environs of the general hospital rather than in an isolated institution, and the patients should be in the clinical charge of a special physician. More needs to be done to arrange temporary admissions of patients for their own benefit and for the relief of relatives, and to organize holidays in a new setting.

1 The Welfare of Children in Hospital. Report of Committee of the Central Health Services Council. 1959. H.M.S.O.

- Report on the Census of Children and Adolescents in Non-Psychiatric Wards of National Health Service Hospitals. Ministry of Health. 1967. H.M.S.O.

- Rankine, R. and Weir, R. M. L., An Enquiry into the Incidence of Chronic Illness and Disability in the Young and Middle-Aged. 1967. Victoria Hospital, Kirkcaldy, Fife.

- The Rehabilitation, Training and Resettlement of Disabled Persons. Cmnd. 9883. 1956. H.M.S.O.
These two reports merit careful study, and point the way to a more active policy to alleviate the lot of these unfortunate, but not always recognized, children and young and middleaged people suffering from long-term disability and sickness

\section{Pulmonary Embolectomy}

When Trendelenburg ${ }^{1}$ first told of his method of removing pulmonary emboli his vision and daring were received with enthusiasm. Sadly, the patient's strength was rarely able to match the surgeon's skill, and only a few cases of emergency embolectomy were successful. The development of cardiac surgery and the heart-lung bypass machine brought a new understanding of the physiology and surgery of the heart, and the possibility of successful pulmonary embolectomy became real. Now all cardiac surgeons practise emergency embolectomy, most of them using the heart-lung bypass, ${ }^{2-4}$ but some good results have been achieved without it. ${ }^{5}$ It is no longer a question of whether an embolectomy can be done, but when is the right time to do it.

Pulmonary embolism presents in four ways: firstly, sudden death ; secondly, collapse, hypotension, and right heart failure followed by death or slow recovery over a few hours; thirdly, sudden severe pain, haemoptysis, and collapse followed by a steady, sometimes rapid, cardiovascular recovery; and, fourthly, without clinical disturbance of the cardiovascular system.

In making the diagnosis the surgeon will in some cases note the clinical signs of peripheral vascular collapse, high central venous pressure, third heart sounds, characteristic changes in the E.C.G., and the absence of vascular markings on the chest radiograph. These are diagnostic if they are all present, but unfortunately many cases do not have these physical signs. Consequently some surgeons advocate doing a preoperative pulmonary angiogram to avoid operating on a coronary infarction-the main differential diagnosis. This takes time, as does lung scanning after the injection of labelled macroaggregates of albumin, and often there is no time to spare.

The approach to the management of the four clinical groups is slowly evolving along the following lines. Sudden death from pulmonary embolism should be treated by external cardiac massage, for in some cases the massage will break up the thrombus, move it on, and so allow some pulmonary blood flow. If the circulation is restored and the patient responds, then the massage is continued until the patient is anaesthetized and either put on a heart-lung bypass or given supportive perfusion with blood taken from the femoral vein, oxygenated, and returned to the arterial circulation. There is obviously no time to confirm the diagnosis before operation, and so it must be accepted that a certain number of these patients will

\footnotetext{
1 Trendelenburg, F., Langenbecks Arch. klin. Chir., 1908, 86, 686.

2 Hayward, J., and Howqua, J., Lancet, 1964, 2, 771.

- Makey, A. R., and Bliss, B. P., ibid., 1966, 2, 1155.

- Paneth, M., \%. thorac. cardiovasc. Surg., 1967, 53, 77.

Vosschulte, K., Stiller, H., and Eisenreich, F., Swrgery, 1965, 58 317.

Wagner, H. N., Sabiston, D. C., McAfee, J. G., Tow, D., and Stern. H. S., New Engl. f. Med., 1964, 271, 377.

r Browse, N. L., and James, D. C. O., Lancet, 1964, 2, 1039.

- Hirsh, J., Hale, G. S., McDonald, I. G., McCarthy, R. A., and Cade. J. F., ibid., 1967, 2, 593.

Gorham, L. W., Arch. intern. Med., 1961, 108, 8.

to Paneth, M., Ann. roy. Coll. Surg. Engl., 1967, 41, 370.

11 Barker, N. W., and Priestley, J. T., Surgery, 1942, 12, 411.

12 Phear, D., Lancet, 1960, 2, 832.

13 Allison, P. R., Dunnill, M. S., and Marshall, R., Thorax, 1960, 15. 273.
} 
be found to have a normal pulmonary artery and an infarcted myocardium.

Those who collapse and remain very ill require surgical treatment, or possibly thrombolytic therapy. ${ }^{78}$ But there is usually time for diagnostic investigations, ${ }^{9}$ and emergency pulmonary angiography is of great help. Embolectomy can then be done, and this is the group of patients in whom the best results are obtained. ${ }^{10}$ It is difficult to decide when to operate, but failure to improve over one to three hours, with bypotension and a raised central venous pressure, are sound indications for surgery.

The third group, collapse followed by fairly rapid recovery, presents many problems. Though surgery is not needed to save life, two great risks threaten these patients. Firstly, there may be another embolus waiting in the legs which, added to the first, could kill (second emboli occur in 30\% of patients). ${ }^{11}$ Secondly, early cardiovascular recovery does not mean that the patient will ultimately attain normal health. D. Phear ${ }^{12}$ has shown that $30 \%$ of patients who survive a major embolism have persistent and sometimes disabling dypsnoea, due either to the initial embolus or to recurrent small subclinical emboli. It seems reasonable to suggest that these patients should have their peripheral veins studied, as suggested by N. L. Browse and his colleagues (p. 596), and a pulmonary angiogram done, and then be considered for thrombolytic therapy or surgery. How much time is available for these investigations before the thrombus becomes so adherent that it is irremovable? The paper by Lord Brock and his colleagues published at page 598 of the B.M.F. this week sheds light on this question, for it shows that emboli can sometimes be removed months after impaction. Many cardiovascular surgeons have operated on pulmonary and peripheral arterial emboli after impaction and found some: to be irremovable and others loose. More information is. required about the natural history of emboli. Though they undergo lysis spontaneously and rapidly in the dog, ${ }^{13}$ there is ample clinical evidence to prove that this does not always happen in man. The increasing use of pulmonary embolectomy should expand our knowledge of the local lesion in the pulmonary artery.

The present trend is to be bold not only to save life but also to reduce the late morbidity. But this approach needs to be continually reviewed in accordance with the findings at operation and the long-term results.

\section{Doctors' Diseases}

In the evidence which the B.M.A. submitted to the Goodenough Committee it deplored the failure of the medical schools to exclude men and women who, though able to pass examinations, have not the requisite aptitude, character, or staying power for a medical career. The Committee agreed, and recommended ${ }^{1}$ that there should be machinery not only to select students from this standpoint but also to weed out students who prove unsuitable. No one, however, was bold enough to state the criteria of rejection, or, more specifically, to say whether a propensity to some form of psychological illness should be regarded as a sign of unsuitability. Deans of medical schools might have very discrepant views on this matter, and on their ability to look sufficiently into the future of some nervous aspirant aged 18 or 19 to foretell his professional fitness or inadequacy. Nevertheless, the attempt has to be made, for the health and mental stability of doctors are matters of public as well as private concern. It is therefore understandable that the authors ${ }^{2}$ of a recent inquiry should express their surprise that there have been few studies of the amount of psychiatric illness in the medical profession. Their own findings are not particularly encouraging.

A hundred and ninety-two doctors who had been treated at either St. Andrew's Hospital, Northampton, or St. George's Hospital, London, were compared with "control" groups, presumably free from psychiatric illness. There were no differences between the doctors and non-medical patients (matched for age, sex, and social class) in the frequency of most sorts of disorder, except that neurotic depressive reactions and drug addiction were more common in doctors. Psychiatrically disturbed doctors showed a greater tendency than usual to fall by the wayside professionally ; only $70 \%$ were on the Medical Register when followed up in 1964.

The proportions in which various branches of the profession were represented in the sample do not permit any simple conclusion to be drawn. General practitioners made up 53\%, $12 \%$ were psychiatrists, and $11 \%$ were surgeons. A similar investigation $^{3}$ of 93 doctors admitted to the Mayo Clinic for psychiatric treatment between 1956 and 1963 showed that 44 were general practitioners (about the same proportion as in the profession as a whole), 15 were physicians, 17 were surgeons, and 4 were psychiatrists. Evidently no single branch of the profession has a disproportionate pre-eminence in this respect. A third of the doctors had some form of psychotic illness, a fifth were neurotic, and most of the remainder had personality disorders. Treating them was exceptionally difficult because the doctors found it hard to accept the status of a patient and tended to withdraw from treatment too soon.

There are two aspects of psychiatric illness which are painfully prominent in this connexion-suicide and drug addiction. Analysis of the Registrar General's Decennial Supplement earlier in this century ${ }^{4}$ showed that among the occupational groups with the highest suicide rates were doctors and lawyers. It has been conjectured that this was because they "work under some degree of nervous pressure" and witness much misery and suffering. In a recent study ${ }^{5}$ in Oregon the suicide rate for doctors and lawyers was found to be three times as high as in "white-collar workers." Despite the known unreliability of official statistics of suicide, it must be regarded as an occupational disease of medical practice. ${ }^{6}$

The problem of addiction in doctors has also been long recognized. The Rolleston Departmental Committee ${ }^{7}$ that reported in 1926 said that " questions of exceptional difficulty have presented themselves in the cases of doctors who are themselves addicts," and the Brain Committee ${ }^{8}$ echoed this, pointing out that the number of doctors known to be addicts was disproportionately high. There were in Britain in 1960 68 "professional" addicts-doctors, dentists, pharmacists,

\footnotetext{
1 Report of the Inter-departmental Committee on Medical Schools, 1944. H.M.S.O., London. Out of print.

3 A'Brook, M. F., Hailstone, J. D., and McLauchlan, I. E. J., Brit. J. Psychiat., 1967, 113, 1013.

Duffy, J. C., and Liten, E. M., F. Amer. med. Ass., 1964, 189, 989.

Dublin, L. I., and Bunzel, B., To be or not to be-a study of suicide, 1933. New York.

Blachly, P. H., Osterud, H., and Josslin, R., New Engl. F. Med., 1963, 268, 1278.

- Brit. med. f., 1964, 1, 789. Report of the Departmental Committee on Morphine and Heroin
Addiction, 1926. H.M.S.O., London.

- Drug Addiction: Report of, the Interdepartmental Committee, 1961. H.M.S.O., London.

- Ehrhardt, Ḧ., Bull. Narcot., 1959, 11, No. 1, p. 18.

10 Pearson, M. M. and Strecker, E. A., Amer. f. Psychiat., 1960, 116. 915.

11 Putnam, P. L., and Ellinwood, E. H., ibid., 1966, 122, 745.

12 Evans, J. L., ibid., 1966, 122, 159.
} 